\title{
Design of Three-Layer Shielded Microstrip Line for Microwave Circuit Applications by Applying Cole-Cole Diagrams
}

\author{
Settapong Malisuwan and Jesada Sivaraks
}

\begin{abstract}
A new model for a three-layer shielded microstrip line for microwave circuit applications is presented. Similar to dielectric relaxation considerations of Cole-Cole diagrams which was applied to dielectric materials, a "reactive relaxation" idea is introduced to embody the frequency-dependent characteristics of the micro strip line. This research is expedient for researchers as it proposes simple yet efficient methods that can explain physical aspects of micro strip circuits while ensuring precision.
\end{abstract}

Index Terms-Cole-Cole diagrams, debye relation, microstrip, nonfringing energy

\section{INTRODUCTION}

The advent of new technologies has lead Radio Frequency (RF) and microwave engineers to design future ultra-fast digital circuits by increasing component density. Several researchers [1]-[3] proposed closed-form expressions for analyzing the high-speed microstrip transmission lines. Most computer-aided design (CAD) systems have been formed by utilizing this kind of algorithm that has built-in microstrip design capabilities. However, simple calculation technique for microstrip line parameters such as using hand-calculator or personal computer is needed for the initial design stage or for quick circuit evaluation purposes. Designers are also required to scrutinize fragmentally the physical components of microstrip circuits. Researchers are searching for simple yet effective methods in explaining the physical aspects of the microstrip circuits which ensure accurateness.

The contribution of this research is the analysis of the three-layer shielded microstrip line performance based on the Cole-Cole diagram representation [4]. To achieve this goal, an approach that uses the Debye relation [4] is introduced to portray frequency-dependent characterization of a microstrip line. Hence, "a reactive relaxation diagram" (analogous to the Cole-Cole diagram) is proposed to represent the frequency-dependent capacitive effects in the three-layer shielded microstrip line.

Generally, it is time consuming and expensive to employ numerical approaches because it requires high performance computer for microstrip synthesis (or analysis) leading to computer-aided circuit design. However, the expressions derived in this paper are simpler and computationally

Manuscript received January 9 2013; revised March 15, 2013. Full financial support for this paper is from National Broadcasting and Telecommunications Commission.

The authors are with the National Broadcasting and Telecommunications Commission, Bangkok, Thailand (e-mail: settapong.m@nbtc.go.th, jesada.s@nbtc.go.th). economical in terms of time and system requirements.

\section{DisPersion MODEl OF A THREE-LAYER SHIELDED MICROSTRIP LINE}

The three-layer shielded microstrip line used in this research is the open transmission line. The geometry of the microstrip line is shown in Fig. 1.

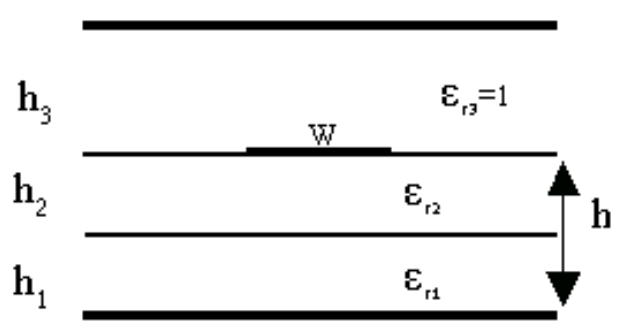

Fig. 1. Three-layer shielded microstrip line

The frequency-dependent effective permittivity of the three-layer shielded microstrip line can be written as [5]:

$$
\varepsilon_{e f f}(\omega)=\varepsilon_{r v}(\omega)+\frac{\varepsilon_{e f f}(0)-\varepsilon_{r v}(\omega)}{1+Q(\omega)}
$$

$\varepsilon_{r v}(\omega)$ can be written as a "combination of static and frequency-dependent parts of the relative permittivity" [5] [6].

$$
\varepsilon_{r v}(\omega)=\varepsilon_{e q}+\varepsilon_{\text {radd }}(\omega)
$$

where $\varepsilon_{e q}$ "could be obtained from the SLR formulation" [6]. Additional relative permittivity can be written as

$$
\begin{gathered}
\varepsilon_{\text {radd }}(\omega)=\sqrt{r \Delta \varepsilon_{r}} \frac{\left(1+a \frac{w}{h}\right)}{H}\left(f_{n}\right)^{\beta} \\
f_{p}=\frac{Z_{0}}{2 \mu_{0} h \sqrt{\left(\varepsilon_{\text {eff }}(0)\right)}}
\end{gathered}
$$

where $\omega=2 \pi f$ and $f_{n}$ is the normalized frequency and $H$ is a parameter which controls the thickness of dielectric layers. $Z_{0}$ "is the characteristic impedance of the microstrip line on the air-substrate". $Z_{0}$ could be obtained from the closed-form 
expressions in [7]. The expressions for $\alpha, \beta$, and $\gamma$ are summarized as follows [5]:

Since $\varepsilon_{r 1}>\varepsilon_{r 2}$, therefore, $\varepsilon_{e f f}(f)$ is obtained by taking the following parameters in Eqn. (3):

$$
H=\sqrt{\frac{h_{3}}{h}}, \quad h=h_{1}+h_{2}
$$

For

$$
\begin{aligned}
& f . h \leq 0.8 \mathrm{GHz} . \mathrm{cm} \\
& f_{n}=f_{p} /(2.5(f-\exp (0.035 f))) .
\end{aligned}
$$

For

$$
\begin{aligned}
& 0.8 \leq f . h \leq 2 \mathrm{GHz} . \mathrm{cm} \\
& f_{n}=f_{p} /(2.0(f-\exp (0.035 f))) .
\end{aligned}
$$

For

$$
\begin{aligned}
& 2 \leq f . h \leq 6 \mathrm{GHz} . \mathrm{cm} \\
& f_{n}=\left(f_{p} / 133.78\right)
\end{aligned}
$$

where $f$ and $f_{p}$ are in GHz. $\beta=\gamma=0.5$, and the empirical expression for $\alpha$ is as follows:

$$
\begin{gathered}
a=C_{3}\left(\frac{w}{h}\right)^{-C_{4}}, \quad 0.6 \leq \frac{w}{h} \leq 10 \\
C_{3}=2.7392-14.587\left(\frac{h_{2}}{h_{1}}\right), \quad \frac{h_{2}}{h_{1}} \leq 0.05 \\
=1.9715, \quad 0.05 \leq \frac{h_{2}}{h_{1}} \leq 0.33 \\
=2.1986-0.6821\left(\frac{h_{2}}{h_{1}}\right), \quad 0.33 \leq \frac{h_{2}}{h_{1}} \leq 1 \\
C_{3}=0.4758-0.9732\left(\frac{h_{2}}{h_{1}}\right), \quad \frac{h_{2}}{h_{1}} \leq 0.05 \\
=0.4246, \quad 0.05 \leq \frac{h_{2}}{h_{1}} \leq 0.33 \\
=0.4378-0.03959\left(\frac{h_{2}}{h_{1}}\right), \quad 0.33 \leq \frac{h_{2}}{h_{1}} \leq 1
\end{gathered}
$$

The $\varepsilon_{r v}(f)$ is consistent with the asymptotic requirement with in terms of top shield height, i.e., $\varepsilon_{r v}(f) \rightarrow \varepsilon_{e q}$ for $\left(h_{3} / h\right) \rightarrow \infty$. For $\left(h_{3} / h\right)>8$, the model can also be used to" determine the dispersion behavior of the open composite-substrate microstrip line" [6].

For $\mathcal{E}_{r 2}>\mathcal{E}_{r 1}$, the $\mathcal{E}_{e f f}(f)$ is obtained by taking the following parameters in Eqn. (3):

$$
H=\sqrt{\frac{h_{3}}{h}}, \quad h=h_{1}+h_{2}
$$

For

$$
\begin{aligned}
& f . h \leq 0.8 \mathrm{GHz} . \mathrm{cm} \\
& f_{n}=f_{p} /(2.2(f-\exp (0.035 f))) .
\end{aligned}
$$

For

$$
\begin{aligned}
& 0.8 \leq f . h \leq 1.2 \text { GHz.cm } \\
& f_{n}=f_{p} /(2(f-\exp (0.035 f)))
\end{aligned}
$$

For

$$
\begin{aligned}
& 1.2 \leq f . h \leq 2.8 \mathrm{GHz} . \mathrm{cm}, \\
& f_{n}=\left(f_{p} / 125\right) .
\end{aligned}
$$

\section{Microstrip-BASED EQUIVALENT RELAXATION PROCESS}

The Debye relation on the relative complex permittivity of a material depicting the dielectric relaxation can be written as [4]:

where $\omega=2 \pi \mathrm{f}$; $\mathrm{f}$ is the applied frequency; and, $f_{r}=1 / \tau_{\mathrm{r}}$ where $\tau_{r}$ is the characteristic relaxation time of the dielectric material. Further, $\varepsilon_{\infty}$ and $\varepsilon_{s}$ are the relative permittivity of

$$
\varepsilon_{m}^{*}(\omega)=\varepsilon_{\infty}+\frac{\varepsilon_{s}-\varepsilon_{\infty}}{1+j 2 \pi\left(\omega / \omega_{r}\right)}
$$

or

$$
\varepsilon_{m}^{*}(\omega)=\left[\varepsilon_{\infty}+\frac{\varepsilon_{s-} \varepsilon_{\infty}}{1+4 \pi^{2}\left(\omega / \omega_{r}\right)^{2}}\right]-j\left[\left(\varepsilon_{s}-\varepsilon_{\infty}\right)+\frac{2 \pi\left(\omega / \omega_{r}\right)}{1+4 \pi^{2}\left(\omega / \omega_{r}\right)^{2}}\right]
$$

The material at very high $(\mathrm{f} \rightarrow \infty)$ and quasi-static $(\mathrm{f} \rightarrow 0)$ frequencies.

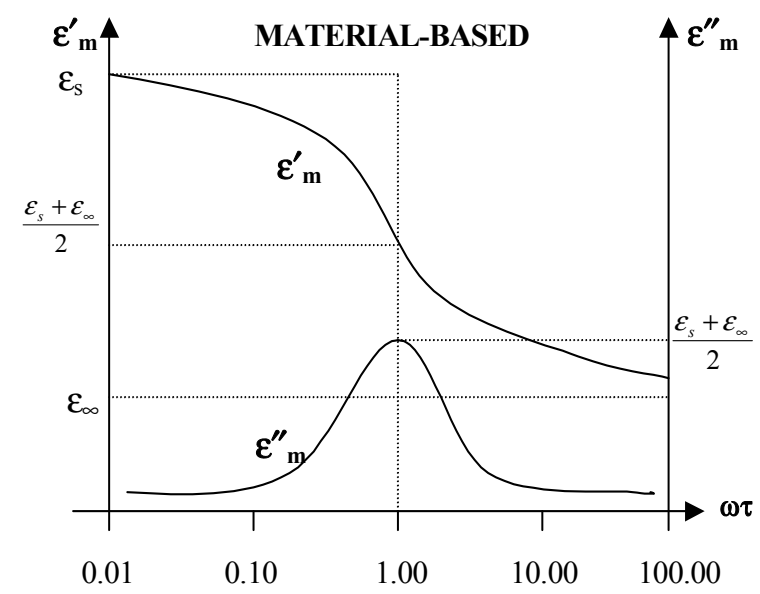

Fig. 2. Dielectric relaxation: debye relation

The real and imaginary parts of the Debye relation are depicted in Fig. 2. The Debye relation can be represented as shown in Fig. 3. It is known as the Cole-Cole diagram. This graphical representation which is of considerable practical importance involves plotting $\varepsilon^{\prime}$ versus $\varepsilon^{\prime \prime}$. The function $\varepsilon^{\prime}\left(\varepsilon^{\prime}\right)$ can be obtained by elimination of $\omega$ between the equations $\varepsilon_{m}^{\prime}(\omega)$ and $\varepsilon_{m}^{\prime \prime}(\omega)$. The functional relation obtained in this 
format can be shown to be a circle. $\mathcal{E}^{*}$ is now presented by the semi-circle of radius $\left(\varepsilon_{s}-\varepsilon_{\infty}\right) / 2$ centered at $\varepsilon^{\prime}=\left(\varepsilon_{\infty}+\varepsilon_{s}\right) / 2$. The top of this semi-circle corresponds to $\omega \tau_{\mathrm{r}}=1$. The relaxation time is calculated from $\tau_{\mathrm{r}}=1 / f_{\mathrm{r}}$. It can be seen that $\varepsilon^{\prime}$ decreases with frequency. This means that the energy stored in the material will decrease with frequency.

This gives,

$$
\begin{gathered}
\varepsilon_{r v}(\omega)=\varepsilon_{\infty} \\
\varepsilon_{e f f}(0)=\varepsilon_{s} \\
\tau_{0}=\underline{\sqrt{Q(\omega)}}
\end{gathered}
$$

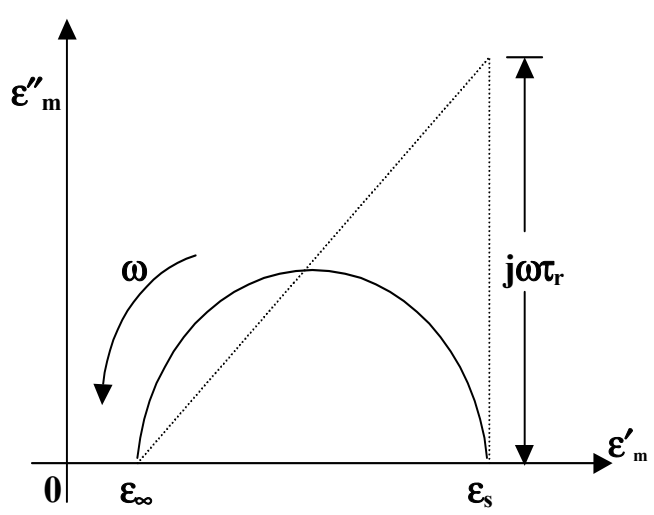

Fig. 3. Cole-Cole diagram of material-based

\section{Cole-Cole Diagram Representation of THREE-LAYER SHIELDED MICROSTRIP LINE}

The concept of dielectric relaxation can be analogously applied to characterize the frequency-dependent performance of a microstrip line. Hence, a frequency-dependent effective permittivity deduced for the three-layer shielded microstrip line [5] can be written in a Debye relation form as follows:

The frequency-dependent effective permittivity in Eqn. (1), it

$$
\begin{aligned}
& \varepsilon_{u}^{\prime}(\omega)=\varepsilon_{e f f}(\omega)=\left[\varepsilon_{r v}(\omega)+\frac{\varepsilon_{e f f}(0)-\varepsilon_{r v}(\omega)}{1+Q(\omega)}\right] \\
& \equiv \operatorname{Re}\left[\varepsilon_{r v}(\omega)+\frac{\varepsilon_{e f f}(0)-\varepsilon_{r v}(\omega)}{1+j(1 / 2 \pi)\left(\omega_{0} / \omega\right)}\right]
\end{aligned}
$$

can be equated to the real part of Eqn. (16b) as follows.

$$
\begin{gathered}
\varepsilon_{e f f}(\omega)=\varepsilon_{r v}(\omega)+\frac{\varepsilon_{e f f}(0)-\varepsilon_{r v}(\omega)}{1+Q(\omega)} \\
=\varepsilon_{\infty}+\frac{\varepsilon_{s}-\varepsilon_{\infty}}{1+4 \pi^{2}\left(\omega / \omega_{r}\right)^{2}}
\end{gathered}
$$

Now the "imaginary part" of the equivalent permittivity of a microstrip system can be obtained by applying Eqns. (19)-(21) into the imaginary part of Eqn. (16b). Hence, the imaginary part of Cole-Cole expression for a microstrip system can be written as

$$
\varepsilon_{u}^{\prime \prime}(\omega)=\left[\frac{\left(\varepsilon_{e f f}(0)-\varepsilon_{r v}(\omega)\right) \sqrt{Q(\omega)}}{1+Q(\omega)}\right]
$$

Therefore, the complex permittivity of microstrip system in compact form can be written as:

$$
\varepsilon_{u}^{*}(\omega)=\varepsilon_{r v}(\omega)+\frac{\varepsilon_{e f f}(0)-\varepsilon_{r v}(\omega)}{1+j(1 / 2 \pi)\left(\omega_{0} / \omega\right)}
$$

In theory, the maximum points of semi-circles in the Cole-Cole patterns correspond to maximum Debye loss in a dielectric material [8] but, in respect to themicrostrip system, these points can be used to depict the maximum reactive (capacitive) energy confined within the microstrip structure That is pertinent to the maximum value point (A) in Fig. 4. Therefore, it can be considered that the microstrip geometry holds the field within itself, rather than letting it fringe out.

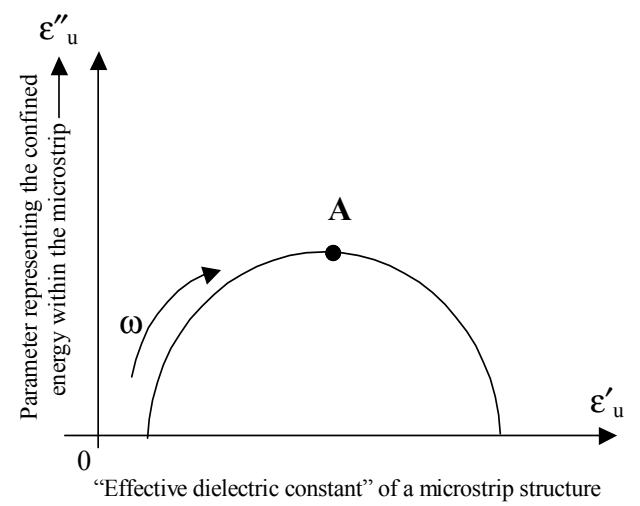

Fig. 4. Cole-Cole representation of reactive relaxation of the three-layer shielded microstrip line

\section{Simulation ANd Result}

Two lossless dielectric substrates are chosen for this study which are $\varepsilon_{r 1}=2.2$ and $\varepsilon_{r 2}=9.7$. The line-width to substrate thickness ratio $w / h$ is taken as $1.0,2.0$, and 4.0. with $h 1=$ $0.053 \mathrm{~cm}, h 2=0.097 \mathrm{~cm}, h 3=0.159 \mathrm{~cm}$, and $h=h 1+h 2$.

Considering the equivalent Cole-Cole diagram of the test microstrip depicted in Fig. 5, the simulation results reveal that the nonfringing part of the reactive energy in the microstrip reduces when the $w / h$ ratio increases. For example, about $10 \%$ reduction of this nonfringing energy is observed $z$

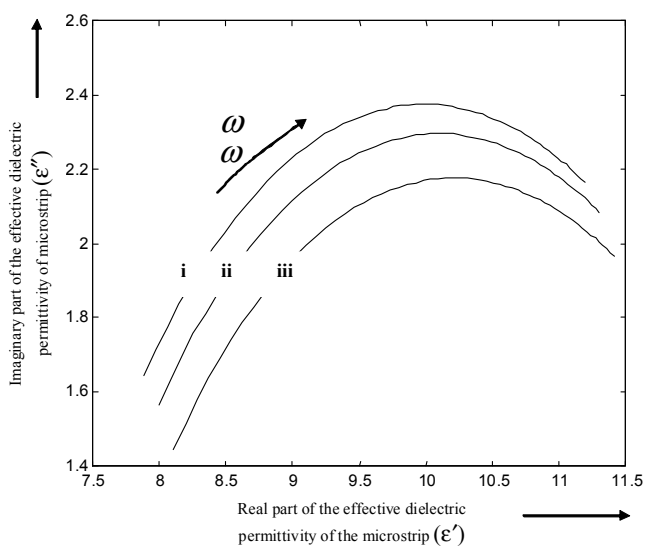


Fig. 5. Cole-COLE diagrams of the three-layer shielded microstrip line: $\varepsilon \mathrm{r} 1=2.2, \mathrm{\varepsilon r} 2=9.7, \mathrm{~h} 1=0.053 \mathrm{~cm}$ and $\mathrm{h} 2=0.097 \mathrm{~cm}$.

(i) $\mathrm{w} / \mathrm{h}=1.0$ ( ii ) $\mathrm{w} / \mathrm{h}=2.0$ ( iii ) $\mathrm{w} / \mathrm{h}=4.0$

\section{CONCLUSIONS}

In this paper, the algorithm used to represent the frequency-dependent characteristics of the three-layer shielded microstrip line is based on Cole-Cole dispersion concept. After a thorough research it has been confirmed that proposed model has not been addressed in the literature until now. The research presented in this paper will be a valuable contribution towards computer-aided microwave circuit designs.

\section{ACKNOWLEDGMENT}

The authors would like to thank the review committee for providing recommendations on this paper. We would also like to thank National Broadcasting and Telecommunications Commission for their support.

\section{REFERENCES}

[1] S. Malisuwan and V. Ungvichian, "A study of crosstalk applied to ultra-high-speed parallel lossy microstrip and strip lines with shielding effectiveness," presented at IEEE Int. Symp. on Electromag. Compat., Japan, May 1999.

[2] V. Ungvichian and S. Malisuwan, "The effects of substrate permittivity and pulse-width on the crosstalk as applied to ultra-high-speed microstrip lines," in Proc. IEEE AP-S Int. Symp. and URSI Meeting, Orlando, 1999 , vol. 1, pp. 202-205

[3] T. S. Yeo, C. S. Ng, M. S. Leong, and P. S. Kooi, "Interline coupling of ultra-high-speed pulse propagating on PCB," IEEE Trans. Electromag. Compat., 1993, vol. 35, pp. 401-404

[4] E. Riande and E. Saiz, Dipole moments and birefringence of polymers. Prentice Hall,. New Jersey, 1992, vol. 21 pp. 288-289

[5] A. K. Verma and R. Kumar, "New empirical unified dispersion model for shielded-, suspended-, and composite-substrate microstrip line for microwave and mm-wave applications," IEEE Trans. Microwave Theory Tech., vol. MTT-46, pp.1187-1192, Aug. 1998.
[6] A. K. Verma and G. H. Sadr, "Unified dispersion model for multiplayer microstrip line," IEEE Trans. Microwave Theory Tech., vol. MTT-40, pp. 1887-1891, July. 1992.

[7] M. Kirschning and R. H. Jansen, "Accurate wide-range design equations for the frequency-dependent characteristic of parallel coupled microstrip lines," IEEE Trans. Microwave Theory Tech., vol. MTT-32, pp.83-90, Jan. 1984.

[8] P. S. Neelakanta, Handbook of Electromagnetic Materials, Boca Raton, FL: CRC Press, 1995. ch. 2

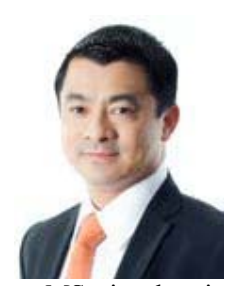

Settapong Malisuwan was born on 24th March 1966 in Bangkok, Thailand. He received his $\mathrm{PhD}$ in electrical engineering (telecommunications), specializing in mobile communication systems from Florida Atlantic University (State University System of Florida), Boca Raton in 2000. He received an MSc in electrical engineering in mobile communications system, from George Washington University in 1996, an MSc in electrical engineering in telecommunication engineering from Georgia Institute of Technology in 1992 and a BSc in electrical engineering from the Chulachomklao Royal Military Academy, Nakhon-Nayok, Thailand in 1990. He served in the Royal Thai Armed Forces for more than 25 years and is currently the Vice Chairman of National Broadcasting and Telecommunications, Bangkok, Thailand. His research interests are in efficient spectrum management and Telecommunications policy and management in Thailand. Col. Dr. Settapong Malisuwan Settapong Malisuwan is currently the Elected Vice Chairman and Board Member in the National Broadcasting and Telecommunications Commission, Thailand.

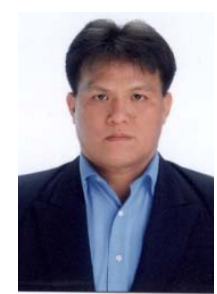

Jesada Sivaraks was born on 12th May 1970 in Bangkok, Thailand. He received his MSEE degree from Oklahoma State University in 1996 and BEng from King Mongkut"s Institute of Technology, Thailand. He completed his $\mathrm{PhD}$ in electrical engineering at Florida Atlantic University, Boca Raton, FL in 2001. Since 2011, he has been working in National Broadcasting and Telecommunications Commission as the Secretary to the Vice Chairman. His $\mathrm{PhD}$ work is on the system aspects of Bluetooth, WLAN and Mobile IP/CDPD. His current research interests are in telecommunication planning and related system analysis and efficient spectrum management. $\mathrm{He}$ is a member of Tau Beta Pi, Florida Epsilon and was an Honorary Advisory's Chairman of Science \& Technology committee of Parliament in 2009 